\title{
O Reconhecimento Contábil dos Gastos Associados às Medidas de Gestão Ambiental no Segmento de Abastecimento de Combustíveis
}

\section{Accounting Recognition of Expenses Associated with Environmental Management Measures in the Fuel Segment}

\author{
Daniel Benitti Lorenzett ${ }^{a}$; Marivane Vestena Rossato ${ }^{b}$; Leoni Pentiado Godoy ${ }^{c}$ \\ ${ }^{a}$ Mestrado em andamento em Engenharia de Produção pela Universidade Federal de Santa Maria, UFSM; \\ Graduação em Ciências Contábeis pela Universidade Federal de Santa Maria, UFSM; \\ Santa Maria, RS - Brasil; E-mail: dlorenzett@gmail.com \\ ${ }^{b}$ Professora da Universidade Federal de Santa Maria, UFSM; Doutorado em Economia Aplicada pela \\ Universidade Federal de Viçosa, UFV; Santa Maria, RS - Brasil; E-mail: marivane@smail.com.br \\ 'Professora da Universidade Federal de Santa Maria, UFSM, Doutorado em Engenharia de Produção pela \\ Universidade Federal de Santa Maria, UFSM; Santa Maria, RS - Brasil; E-mail: leoni_godoy@yahoo.com.br
}

\section{Resumo}

Dada a tendência mundial de sustentabilidade, os postos de combustíveis vêm investindo em gestão ambiental e consequentemente incorrendo em gastos dessa natureza. Tais gastos devem ser adequadamente registrados pela contabilidade ambiental. Assim, o presente estudo buscou analisar o reconhecimento contábil desses gastos segundo as normas brasileiras de contabilidade e literatura específica. Para seu desenvolvimento foi realizada uma pesquisa de campo, através das técnicas de observação e entrevista estruturada. Os resultados revelaram que os gastos com gestão ambiental podem ser registrados como: despesas ambientais, as taxas e licenças ambientais, devendo ser reconhecidas pela utilização dos insumos no setor administrativo; como ativos ambientais, os reservatórios para captação da água da chuva, devendo ser reconhecidos no momento da sua aquisição; ou ainda, como custos ambientais, os valores gastos para manutenção das atividades de proteção e preservação ambiental, devendo ser reconhecidos no momento da sua utilização no processo produtivo.

Palavras-chave: Contabilidade ambiental; Reconhecimento contábil; Postos de combustíveis.

\begin{abstract}
Given the global trend of sustainability, the gas stations have been investing in environmental management, and consequently incurring such expenses. These expenses related to environmental aspects must be properly registered through environmental accounting. Thus, this study investigates the accounting recognition of these expenses according to Brazilian accounting standards and specific literatures. For its development it was developed a field research, where it was applied the observation technique and structured interviews. The results revealed that the expenses with environmental management can be registered as: environmental expenses, taxes and environmental permits, should be recognized by the use of inputs in the administrative sector; as environmental assets, reservoirs to capture rainwater, should be recognized at the time of its acquisition; or as environmental costs, those amounts spent on maintenance of protection activities and environmental preservation, should be recognized at the time of its use in production process.
\end{abstract}

Keywords: Environmental accounting; Accounting recognition; Gas stations. 


\section{INTRODUÇÃO}

A problemática ambiental, apesar de bem antiga, vem tornando-se cada vez mais presente na vida da população global. Atualmente os governos estão se engajando nessa questão, na tentativa de remediar o perigo iminente que assola o planeta. De fato, por muitos anos, o homem, vem degradando o planeta e retirando dele, de forma abusiva e irracional o subsídio para a manutenção da vida humana, afetando, assim, o solo, as águas e o ar, bem como toda forma de vida presente na Terra.

Tendo em vista esse pensamento ecológico, latente, que brota na população mundial, as empresas devem se comprometer com a manutenção sustentável do meio ambiente, para assim garantir a continuidade dos negócios empresariais, tendo na contabilidade ambiental uma ferramenta de evidenciação desse comprometimento, através de seus balanços e demonstrações, onde, ficam evidenciados os investimentos feitos por elas para o controle, preservação e recuperação do meio ambiente.

Quando se dá atenção explícita às boas normas ambientais e as normas contábeis podese ter uma administração superior que por sua vez levará a melhores estratégias, reduzindo os riscos ambientais, sociais e de governança (COLEMAN, 2011). De fato a questão ambiental, é uma preocupação bastante recente. Nesse sentido, o setor de distribuição de combustíveis, caracterizado como uma atividade de alto risco para o meio ambiente, poluindo as águas, o solo e o ar, vem investindo em proteção ambiental e tentando se adequar de forma a tornar essa atividade menos agressiva ao meio ambiente. Nesse âmbito, as administrações públicas juntamente com organizações não governamentais vêem buscando estabelecer normas e procedimentos mais seguros e adequados para tais empresas, que são potencialmente poluidoras (BARROS, 2006; LORENZETT e ROSSATO, 2010,).

A legislação que regulamenta a atividade de armazenamento e distribuição de combustível, no Brasil, data do ano 1997, com a edição da Resolução do Conselho Nacional do Meio Ambiente (CONAMA) n $n^{\circ} .237 / 97$, onde a atividade é citada como sendo sujeita ao licenciamento ambiental. Nesse mesmo ano, a Fundação Estadual de Proteção Ambiental (FEPAM), deu inicio, em nível de Rio Grande do Sul, a um programa de regularização dessas atividades, junto aos sindicatos dos distribuidores, operadores, transportadores e revendedores de combustíveis. Posteriormente, o CONAMA, publicou a Resolução nº. 273/2000, que padroniza os procedimentos, bem como o licenciamento das atividades que possuem armazenagem de combustíveis, como os postos de gasolina (por exemplo LORENZETT e ROSSATO, 2010).

Estas Resoluções são as principais normas existentes na legislação ambiental para o licenciamento ambiental da atividade de posto de abastecimento de combustível. Contudo, o empreendedor desse ramo deve estar atento também às normas técnicas expedidas pelaAssociação Brasileira de Normas Técnicas (ABNT), e a legislação estadual específica de cada Estado, de forma a garantir que seu empreendimento esteja sempre em conformidade com a legislação ambiental especifica (LORENZETT e ROSSATO, 2010). A partir dessa contextualização podese inferir que o grau de preocupação em relação à interação da empresa com o meio ambiente no setor de armazenamento e distribuição de combustíveis, vem aumentando gradativamente, devendo ele adequar-se às normas estabelecidas pelos órgãos competentes.

Diariamente surgem novas demandas e novas necessidades por informações de caráter financeiro-ambiental nas empresas (FARONI, et al., 2010). O processo de adequação às normas técnicas ambientais gera gastos às organizações, que devem ser identificados, mensurados e reconhecidos contabilmente de forma adequada, função esta de responsabilidade da contabilidade 
e consequentemente do contador, cabendo a ele levantar os gastos incorridos na adoção de projetos de gestão ambiental, bem como verificar a melhor maneira para o reconhecimento contábil de tais eventos.

Nesse enfoque, apesar de as novas regras contábeis não se aplicarem a todas as empresas, principalmente as limitadas, que representam prováveis oitenta por cento do total das empresas brasileiras (CFC, 2009; WEISS, 2010), é de vital importância que o profissional da área mantenha-se atualizado. Considerando, ainda, que a contabilidade ambiental é um ramo pouco explorado nas ciências contábeis e que os profissionais da área não estão suficientemente familiarizados com os procedimentos por ela adotados, somando-se a essas situações as recentes alterações realizadas na legislação contábil brasileira, surgiu a seguinte dúvida: como deve ser realizado o reconhecimento contábil dos gastos associados às medidas de gestão ambiental adotadas no segmento de abastecimento de combustíveis, de acordo com as normas brasileiras de contabilidade?

As empresas ao desenvolverem suas atividades acabam prejudicando o meio ambiente através da emissão de gases tóxicos na atmosfera, da produção de resíduos e da contaminação e degradação das águas e do solo (COSTA e MARION, 2007; LORENZETT e ROSSATO, 2010). Segundo Martins e Ribeiro (1995), esses prejuízos impostos ao ambiente não são considerados para formação do custo das mercadorias. Sugerindo que a contabilização dos aspectos ambientais de forma segregada nas demonstrações contábeis possibilitaria a visualização mais clara das interações das entidades com o meio ambiente. Assim, a temática em questão surgiu diante à necessidade da obtenção de informações referentes à contabilização dos gastos de caráter ambiental no que tange à regulamentação da atividade de postos de combustíveis e sua interação com o meio ambiente. Tais gastos devem ser mensurados e identificados como custos, despesas ou investimentos para que se possa proceder à contabilização de maneira correta, de acordo como as normas brasileiras de contabilidade.

Cabe ressaltar, que as empresas do segmento de postos de abastecimento de combustíveis são, provavelmente, quase que em sua totalidade empresas limitadas, não estando obrigadas, portanto, a aderirem às normas brasileiras de contabilidade referentes ao registro contábil dos eventos relacionados às atividades ambientais aqui estudadas, mas estas empresas podem sim aderir a tal forma de contabilização para fins de controle gerencial.

Outro fator importante que foi estudado diz respeito à evidenciação desses gastos, se essa evidenciação deve ocorrer no corpo das demonstrações contábeis ou segregada delas, em outros relatórios, de forma a transparecer a preocupação da empresa com o meio ambiente. Para Ribeiro (2006), a correta mensuração e evidenciação, são importantes, pois fornecem aos gestores informações confiáveis e apropriadas sobre os gastos com o controle ambiental. Somente assim, eles poderão proceder de forma eficiente e eficaz o processo de tomada de decisão com relação à adequada alocação dos recursos na entidade, identificando quais processos incorrem em mais gastos dessa natureza e, corrigindo possíveis falhas para redução dos resíduos, no intuito de evitar prováveis custos decorrentes da atividade e consequentemente impactando com menor intensidade o meio ambiente.

Nesse contexto, pretendeu-se chamar atenção para a problemática ambiental, para as medidas que estão sendo adotadas pelos órgãos competentes em prol do meio ambiente, para o posicionamento do empresário da atividade de comércio de combustíveis perante a legislação ambiental e das medidas que estão sendo tomadas por ele para proteção e preservação do meio ambiente. Diante essas questões, justificou-se a necessidade do estudo realizado, sobre a maneira mais adequada para o reconhecimento contábil dos gastos associados às medidas de 
gestão ambiental no segmento de abastecimento de combustíveis.

Apesar das empresas limitadas, não estarem obrigadas a aderirem a essa contabilização ambiental, sua adoção por todas as entidades que interagem com o meio ambiente, principalmente aquelas potencialmente poluidoras, é de grande importância, uma vez que, a partir de gastos adequadamente mensurados, reconhecidos e evidenciados, a contabilidade estaria realizando sua função social, ao permitir aos usuários internos (gerentes, sócios, cotistas ou acionistas) e externos (sociedade), através das demonstrações contábeis, a visualização dos aspectos ambientais inerentes a essas entidades. Principalmente no caso dos usuários internos, onde serviria como ferramenta para o controle gerencial.

Este estudo objetivou pesquisar o reconhecimento contábil dos gastos decorrentes da adaptação à legislação, que regulamenta o setor de abastecimento de combustíveis. Pretendeu-se, basicamente, demonstrar o adequado reconhecimento contábil dos gastos associados às medidas de gestão ambiental neste segmento. Especificamente foram identificados e classificados os gastos associados às medidas de gestão ambiental adotadas e analisado o reconhecimento e a evidenciação contábil desses gastos de acordo com a Norma de Procedimento de Auditoria - NPA 11, do Instituto de Auditores Independentes do Brasil (IBRACON), e com as Normas Brasileiras de Contabilidade NBC T 15 e NBC TE, do Conselho Federal de Contabilidade (CFC), e demais literaturas específicas.

\section{REFERENCIAL TEÓRICO}

\subsection{Contabilidade geral}

A ciência contábil tem como objeto o patrimônio das entidades, de forma a estudar o controle dos fatos decorrentes da gestão desse patrimônio, permitindo, assim, a obtenção de informações financeiras acerca da entidade. Segundo, Ribeiro (1999, p.14), contabilidade "é uma ciência que permite, através de suas técnicas, manter um controle permanente do Patrimônio da empresa."

Já para Franco (1997, p. 21), a contabilidade é:

a ciência que estuda os fenômenos ocorridos no patrimônio das entidades, mediante o registro, a classificação, a demonstração expositiva, a análise e a interpretação desses fatos, com o fim de oferecer informações e orientação - necessárias a tomada de decisões - sobre a composição do patrimônio, suas variações e o resultado econômico decorrente da gestão da riqueza patrimonial.

De acordo com Iudícibus et al. (2006), a informação contábil possui duas finalidades, a de controle e a de planejamento, sendo útil como meio de comunicação, de motivação e de verificação. Quanto ao controle, infere-se a verificação no que tange a atuação da entidade em conformidade com os planos, metas, políticas e normas traçadas. Já o planejamento, irá fazer uso da informação contábil para projetar diversos caminhos que a empresa deverá seguir no futuro, demonstrando qual é o melhor.

É importante salientar que para se proceder à escrituração dos eventos pertinentes à entidade deve-se ter sempre em mente os princípios fundamentais de contabilidade. Esses princípios representam a essência das doutrinas e teorias relativas à ciência da contabilidade. São princípios fundamentais de contabilidade: o da entidade, o da continuidade, o da oportunidade, o do registro pelo valor original, o da atualização monetária, o da competência e o da prudência. Para este estudo importou, em especial, os seguintes princípios fundamentais de contabilidade: 
a) Princípio da Oportunidade: Segundo CFC (2008) a Resolução CFC nº 750/93 na seção III, determina, por meio desse princípio que os registros sejam feitos imediatamente, atendendo a tempestividade, ou seja, a informação é gerada em tempo certo refletindo a realidade do fato contábil, imprimindo maior confiabilidade à informação gerada.

b) Princípio do Registro pelo Valor Original: Segundo CFC (2008), na Resolução CFC $n^{\circ} 750 / 93$, seção IV, fica estabelecido este princípio, determinando que os componentes do patrimônio devem ser registrados pelos valores originais das transações, expressos em moeda corrente do país a valor presente.

c) Princípio da Competência: Esse princípio, segundo CFC (2008), estabelecido na seção VI da Resolução $C F C n^{\circ} 750 / 93$, determina que as receitas e despesas devam ser reconhecidas na apuração do resultado em que ocorrer, independentemente de seu recebimento ou pagamento.

Outra definição importante para este estudo é a definição de Ativo Operacional, que pode ser entendido como os bens e direitos decorrentes de transações passadas, que estão à disposição da entidade e proporcionarão a ela efetivos benefícios econômicos futuros (SANTOS, SCHMIT e MACHADO, 2005). Segundo esses autores, a definição de ativo está relacionada a situações e eventos econômicos reais, tendo em vista, a confecção dos relatórios contábeis que deverão conter informações úteis aos gestores para a tomada de decisão.

\subsection{Contabilidade ambiental}

Alcançar e manter um ambiente sustentável exige mais do que demonstrações contábeis que contemplem as interações da entidade com o meio ambiente. Para tanto se faz necessário promover ações que incluem o cumprimento das legislações, regulamentação da gestão dos recursos, execução de planos e métas, e educação ambiental. A contabilidade ambiental pode contribuir informando quanto aos resultados referentes às relações da empresa como meio ambiente, mas é preciso ir muito além para que tais dados possam ser uteis a humanidade, na preservação e manutenção dos ecossistemas (JORDAN, et al., 2010).

A Contabilidade Ambiental é um dos ramos da Contabilidade que serve para demonstrar e evidenciar as relações entre as empresas e o meio ambiente, estudando o patrimônio ambiental das entidades e fornecendo informações acerca dos eventos ambientais que promovem alterações no patrimônio (TINOCO e KRAEMER, 2004; FARONI, et al., 2010). Assim, é indispensável que o profissional contábil seja especializado em determinadas áreas do conhecimento e não apenas, tenha formação em contabilidade geral pois os relatórios contábeis são o resultado do processo de escrituração contábil, gerados de forma a fundamentar a tomada de decisões por parte da administração da entidade. Para que esses relatórios possam ser realmente relevantes à tomada de decisão, é necessário, que o contador entenda um pouco mais a fundo alguns aspectos que serão alvo de análise pelo usuário da informação, e é a partir dessa constatação que se fundamenta a necessidades de especializações em contabilidade.

Para Ribeiro (2006, p.39), sob a ótica contábil “o que se pode medir e fazer constar, nas demonstrações contábeis, são os eventos e transações econômico-financeiros, que refletem a interação da empresa com o meio ambiente". Para a autora o combate à destruição do planeta é obrigação de todos, cabendo à contabilidade dar sua contribuição para tal. A autora, explica que a interação da entidade com o meio ambiente ocorre quando se capta do meio ambiente os recursos naturais renováveis ou não, pois se está utilizando do patrimônio da humanidade, e que quando da extração indiscriminada desses recursos, afetaria negativamente esse patrimônio, 
pois pode culminar com sua extinção.

Segundo Ribeiro (2006, p.45) “a contabilidade ambiental não é uma ciência nova, mas sim, uma adaptação da tradicional". Afirma, ainda, que o objetivo dessa contabilidade é:

[...] identificar, mensurar e esclarecer os eventos e transações econômico-financeiros que estejam relacionados com a proteção, preservação, e recuperação ambiental, ocorridos em um determinado período, visando à evidenciação da situação patrimonial de uma entidade.

Para o CFC (2009, p.3), a contabilidade ambiental:

[...] tem o objetivo de identificar, mensurar, reconhecer e divulgar os aspectos econômico-financeiros inerentes aos eventos e às transações relacionados à interação da entidade com o meio ambiente; está inserida no sistema contábil, não se configurando como uma contabilidade à parte.

Nota-se, assim, que os dois conceitos não divergem quanto à conceituação e objetivo da contabilidade ambiental, entretanto o segundo é mais abrangente, ao mencionar a inserção da contabilidade ambiental no sistema contábil usual. Outra questão importante é o entendimento do significado do termo mensuração. Assim, quando se fala em mensurar, o que se pretende fazer é valorar economicamente o resultado dos impactos ambientais provocados pelas atividades empresariais (LIMA e VIEGAS, 2002).

A contabilidade ambiental pode ser considerada como um importante instrumento para percepção do papel que o meio ambiente desempenha na economia. Através das contas ambientais pode-se obter dados que destacam a contribuição dos recursos naturais para o bemestar econômico e social, assim como os custos impostos pela poluição e pela degradação dos recursos naturais (PROTOGEROS et al., 2011). Embora esse ramo da contabilidade tenha progredido muito nos ultimos anos, ainda não se encontra largamente difundido, muito em função da dificuldade de implantação das práticas de contabilidade ambiental, o que poderá vir a mudar para os próximos anos, por meio da adoção de módulos de contabilidade ambiental integrados a sistemas convencionais de gestão (BENNET et al., 2004; PROTOGEROS et al., 2011).

Para que se possa entender plenamente a contabilidade ambiental torna-se necessário o conhecimento de alguns conceitos relevantes a respeito das interações das entidades com o meio ambiente. Primeiramente seria interessante conceituar Meio ambiente, para CFC (2009), o Meio ambiente "é o conjunto de condições, leis, influências e interações de ordem física, química e biológica, que permite, abriga e rege a vida em todas as suas formas." Assim, as alterações, positivas ou negativas, das propriedades do meio, causadas por entidades, comparativamente com a situação existente antes do início das atividades, constituirão o impacto ambiental. Na sequência, torna-se necessária a conceituação de ativo e passivo ambiental. Segundo o CFC (2009. p. 3), ativo ambiental é “[...] o recurso controlado pela entidade, cujos benefícios futuros esperados estejam diretamente associados com a proteção do meio ambiente, ou com a recuperação daquele já degradado. Incluem-se também as áreas nativas mantidas para conservação."

Este conceito remete aos bens e direitos controlados pela entidade que estejam diretamente relacionados às atividades de proteção, preservação e recuperação ambiental, inclusas, ainda, as áreas verdes, adquiridas e mantidas na forma de reservas ambientais. Segundo o IBRACON (1996), através da Norma e Procedimento de Auditoria - NPA 11 devem ser considerados como ativos ambientais aqueles bens adquiridos ou construídos com vida útil superior a um ano, no intuito de proteger e preservar o meio ambiente. 
Uma das maiores dificuldades no entendimento da Contabilidade Ambiental consiste na classificação de um elemento em operacional ou ambiental. Entende-se por operacional todo e qualquer item que estiver relacionado às atividades básicas de funcionamento da empresa. Já os itens ambientais serão aqueles ligados à prevenção e diminuição e recuperação dos impactos ambientais (COSTA e MARION, 2007). Assim, as aquisições específicas para o tratamento de resíduos, com o objetivo de proteção e preservação devem ser consideradas como ativos ambientais, ao passo que aquelas realizadas para redução da emissão de gases, por exemplo, devem ser consideradas como ativos operacionais, pois as empresas estão obrigadas por força de lei a uma produção limpa (RIBEIRO, GONÇALVES e LIMA, 2002; SOUZA e RIBEIRO, 2004; COSTA e MARION, 2007).

Quanto ao passivo ambiental, o CFC (2009, p. 4), o define como as:

[...] obrigações para com terceiros resultante de impactos causados ao meio ambiente. Pode se constituir na obrigação de recuperação de áreas degradadas, indenização de terceiros em função dos efeitos de danos ambientais, obrigações de criar meios de compensação para minimizar danos ambientais e, ainda, multas e penalidades semelhantes por infração à legislação ambiental.

Aqui, é possível observar que o passivo ambiental está intimamente relacionado aos impactos ambientais, sendo considerado como os valores dispêndios na recuperação desses danos causados. Entretanto cabe ressaltar que nem sempre o passivo ambiental estará ligado à atividade de recuperação ambiental ou de reparação de danos, mas também poderá aparecer na forma de medidas de controle e preservação ambiental (TINOCO e KRAEMER, 2004; RIBEIRO, 2006; BERTOLI e RIBEIRO, 2006). É o caso da aquisição de equipamentos antipoluentes a prazo ou financiados, onde a contrapartida do investimento registrado no ativo será um registro das parcelas a pagar no passivo, a este tipo de passivo ambiental pode-se dar o nome de obrigação justa (SOUZA e RIBEIRO, 2004).

O IBRACON (1996), ainda define como passivos ambientais aqueles investimentos necessários para reabilitar o meio ambiente agredido e discorre sobre a eliminação do passivo ambiental através de um levantamento. Primeiro, dos passivos ambientais por especialistas, o que se subentende, na realidade, ser um levantamento dos impactos ambientais provocados e não do passivo. A segunda ação seria a elaboração de um plano diretor de meio ambiente, contendo as ações a serem adotadas para redução ou eliminação da degradação provocada, em seguida finalizaria com a execução do plano diretor de meio ambiente, ficando a empresa obrigada e executá-lo sob pena de incorrer em sanções pelos órgãos competentes.

O registro correto dos passivos ambientais é muito importante na contabilidade das empresas, pois quando esses elementos não se encontram corretamente identificados pode ocorrer um comprometimento na sua manutenção, que consequentemente poderá vir a acarretar grandes prejuízos aos indivíduos envolvidos, uma vez que eles não terão subsídios para realizar uma correta e real avaliação da situação empresarial, não podendo julgar com clareza a viabilidade de se investir na entidade (BERTOLI e RIBEIRO, 2006). O passivo ambiental representa obrigações com terceiros, e essas obrigações devem ser reconhecidas no ato de sua verificação, ainda que não tenham sido cobradas ou pagas, e na impossibilidade de mensurar os passivos ambientais deve-se utilizar de notas explicativas para inseri-los (RIBEIRO e LISBOA, 1999).

Para o desenvolvimento do trabalho em questão, foi necessário, diferenciar os gastos de natureza ambiental em despesas e custos ambientais. O CFC $(2009$, p.4), define as despesas de natureza ambiental como "gastos gerais que tenham relação com o meio ambiente, realizados no período, e que não estejam relacionados especificamente com o processo produtivo 
da entidade". Segundo Ribeiro (2006), considera-se despesas ambientais todos os gastos envolvidos no gerenciamento ambiental, que sejam consumidos no período e incorporados na área administrativa.

Nesse sentido, serão consideradas despesas de natureza ambiental, todas aquelas que incorrem em qualquer departamento que desenvolva atividades relacionadas à proteção do meio ambiente. Ribeiro (2006, p.51), ainda, afirma que "esses gastos devem ser contabilizados como despesas do exercício em curso; embora alguns possam ter relação com benefícios futuros, dificilmente estes poderiam ser associados ou mensurados com clareza". A autora considera como exemplo de despesas ambientais no departamento de recursos humanos, a quantidade de horas trabalhadas para recrutamento do pessoal que irá trabalhar na atividade ambiental. Outro exemplo seriam os insumos consumidos na atividade de compra, pesquisa e seleção de materiais necessários às atividades ambientais.

Para o CFC (2009), os custos de natureza ambiental serão aqueles consumidos no processo produtivo com o objetivo de reduzir e prevenir danos ambientais causados pelas atividades operacionais ou outros consumos vinculados à produção, desde que reconhecidos pela entidade. Segundo Ribeiro (2006), muitos gastos na área ambiental se comportam como custos, podendo ser agregados ao custo de produção. Para tanto é necessário que eles resultem em benefícios econômicos futuros, melhorando a eficiência nas atividades da empresa, sendo passiveis de identificação.

Ribeiro (2006, p.52), ainda, afirma que são custos ambientais "todos aqueles relacionados, diretamente ou indiretamente com a proteção do meio ambiente." Ribeiro (2006, p.183), diz que "os custos ambientais são representados pelo somatório de todos os custos dos recursos utilizados pelas atividades desenvolvidas com o propósito de controle, preservação e recuperação nesse setor". Para a autora, o reconhecimento dos custos ambientais se processa na mesma proporção em que beneficiar o exercício em curso, sendo levados ao resultado do exercício em que seu fato gerador ocorreu.

Os custos ambientais devem ser reconhecidos independentemente do desembolso no momento de sua ocorrência, respeitando o Princípio Contábil da Competência, devendo ser incorporados ao bem ou serviço que estiver beneficiando, sob condição de que este bem vise única e exclusivamente à preservação do meio ambiente, sendo sua classificação contábil realizada no ativo permanente imobilizado ambiental, e desde que estes custos venham, ainda, aumentar a vida útil do bem incorporador por um prazo superior a um ano (RAUPP, 2002).

Segundo Ribeiro (2006, p.55, apud ONU, 1989, p. 19), “o reconhecimento do consumo ocorrerá quando da percepção de que os gastos realizados não produzirão futuros benefícios econômicos, ou quando da incoerência em um passivo sem a constituição de um ativo". Para a autora, os custos devem ser identificados no exercício em que ocorreram, sendo reconhecidos à medida que forem ocorrendo, ou seja, em mais de um período, quando for o caso.

Ribeiro (2006), entende que os custos prévios utilizados para redução da poluição em períodos posteriores devem ser estimados e alocados ao exercício em curso, onde o fato gerador ocorreu. Para a autora, existe ainda, o custo decorrente do monitoramento da recuperação ou preservação ambiental, o qual existe concomitantemente a atividade econômica explorada, devendo, portanto, ser regularmente contabilizado, segregadamente em contrapartida as receitas obtidas no período. 


\subsection{Normas contábeis aplicáveis à contabilidade ambiental}

A contabilidade Ambiental deve atender no processo de registro dos eventos, a três normas em especial. Trata-se da Norma de Procedimento de Auditoria - NPA 11, do Instituto de Auditores Independentes do Brasil (IBRACON), e das Normas Brasileiras de Contabilidade - NBC T 15 e NBC TE, do Conselho Federal de Contabilidade (CFC).

\subsubsection{Norma e procedimento de auditoria (NPA 11)}

A norma trata da questão ambiental, onde fica evidenciada a necessidade da contabilidade refletir as interações das empresas com o meio ambiente. Para o IBRACON (1996), os elementos patrimoniais que representem Ativos Ambientais devem ser apresentados sob títulos e subtítulos específicos, nas demonstrações contábeis. Estabelece, também, o procedimento de Auditoria ambiental, para verificar a correta classificação e reconhecimento dos eventos ambientais.

Quanto aos aspectos contábeis, a norma define que, a interação da empresa com o meio ambiente deve ser demonstrada no corpo das demonstrações contábeis, em títulos específicos, identificando adequadamente os ativos e passivos ambientais, devendo ainda ser apresentado em notas explicativas, a real posição ambiental da entidade.

\subsubsection{Norma brasileira de contabilidade técnica (NBC T 15)}

A NBC T 15 estabelece os procedimentos para evidenciação das informações de caráter social e ambiental, pertinentes à entidade. Segundo CFC (2004), devem ser evidenciados quanto à interação da empresa com o meio ambiente, todos os investimentos e gastos realizados, inclusive aqueles relativos a multas e indenizações, bem como passivos e contingências ambientais.

\subsubsection{Norma Brasileira de contabilidade técnica (NBC TE)}

Esta Norma vem estabelecer os critérios para o reconhecimento, classificação, mensuração e divulgação dos eventos de natureza ambiental, que envolvem as entidades. Para este trabalho importou, em especial, os eventos relacionados aos custos e despesas ambientais. Assim estes, foram alvo de estudo mais aprofundado.

Quanto aos custos ambientais, segundo CFC (2009), devem ser reconhecidos no período em que houver o consumo do recurso e confrontados com a receita a que estiverem associados. Serão classificados como de produção se estiverem associados a ela, direta ou indiretamente, ou serão incorporados ao custo dos produtos fabricados ou das mercadorias vendidas, quando configurarem gastos decorrentes das externalidades causadas pela entidade. Entretanto, caso seus volumes sejam expressivos, devem ser considerados como despesa ou perda ambiental do período, devendo ainda, ser avaliados e reconhecidos pelo valor do recurso consumido.

Em relação às despesas o CFC (2009), menciona que estas devem ser reconhecidas na medida em que ocorrem, para suprir a relação da entidade com o meio ambiente, não podendo ser associada aos produtos ou processos específicos da atividade desenvolvida. Assim, elas serão classificadas no corpo da demonstração de resultado (DRE), entre as despesas de venda, administrativas e gerais, segregadas em grupo à parte. No tocante à avaliação, elas devem ser 
avaliadas pelo valor do consumo no momento em que ele ocorreu.

Para o CFC (2009, p. 4), a interação da entidade com meio ambiente consiste na "entrada e a saída de recursos da entidade para o meio ambiente e vice-versa durante o desenvolvimento das atividades operacionais, como, por exemplo, na extração de matérias-primas ou descartes de resíduos e embalagens de produtos e insumos".

Entende-se, portanto que a interação da entidade com o meio ambiente abrange desde a extração dos recursos diretamente do meio ambiente, até sua disposição final no processo produtivo. Neste contexto é enfatizada a disposição final dos resíduos, não abrangendo os bens no pós consumo. É importante incluir esses bens nesse conceito, pois ainda que não sejam insumos da atividade, quando vendidos ao consumidor final, e após o término de sua vida útil, tais bens deveriam retornar ao fornecedor para serem eliminados adequadamente, de forma a evitar um possível impacto ambiental.

O impacto ambiental consiste em alterações causadas peles entidades no meio ambiente, a partir de sua entrada em operação. Para o CFC (2009, p. 4), o Impacto ambiental, será "qualquer alteração, positiva ou negativa, das propriedades do meio ambiente causada por entidade, comparativamente com a situação existente antes do início de determinada atividade".

Para garantir a divulgação das informações ambientais o CFC (2009) estabelece que o plano de contas deve ser adequado de forma a contemplar as contas referentes à interação da entidade com o meio ambiente, de forma segregada das demais contas, para dar destaque, sendo as demais informações relevantes, citadas em notas explicativas.

\subsection{Oramo de postos de combustíveis}

O petróleo além de ser o mais importante dos combustíveis fósseis também é a maior fone de energia dessa origem. A cadeia de postos de combustíveis é o setor que trabalha basicamente o comércio varejista de combustíveis fósseis e bicombustíveis, encontrando-se estrategicamente, disposto em todo território nacional de forma a atender o ciclo econômico da nação, uma vez que os transportes no Brasil são predominantemente rodoviários (BARROS, 2006; LORENZETT e ROSSATO, 2010).

No Brasil a Agência Nacional do Petróleo, Gás Natural e Bicombustível (ANP) é o órgão que regulamenta as atividades ligadas aos produtos derivados de petróleo e de bicombustíveis, assim, os empreendedores que tiverem o interesse de desenvolver atividades ligadas a tais produtos devem sujeitar-se as determinação impostas por ela. Tem-se, ainda, o Conselho Nacional do Meio Ambiente (CONAMA), que é o responsável por legislar sobre a atividade e a Fundação Estadual de Proteção Ambiental (FEPAM) que licencia e fiscaliza, em nível de Rio Grande do Sul, o cumprimento das normas estabelecidas e as prefeituras municipais, que são responsáveis pela identificação dos locais adequados ao desenvolvimento da atividade (LORENZETT e ROSSATO, 2010).

O ramo de postos revendedores de combustível, segundo Santos (2005), pode ser classificado em duas categorias em função das atividades neles desenvolvidas, a primeira categoria seria a de posto cidade que é mais voltado para atender às necessidades da população urbana, localiza-se para tanto em perímetro urbano e possuindo estruturas menores. A segunda categoria compreende os postos estrada que são voltados a atender às necessidades dos viajantes e dos caminhoneiros e é localizado geralmente junto às estradas, possuindo uma estrutura relativamente maior em função da disponibilização de estacionamentos para os caminhoneiros e viajantes. 
Ainda, segundo Santos (2005), os postos de combustíveis comumente desenvolvem atividades como: transporte de combustíveis, armazenamento dos combustíveis, abastecimento dos veículos, troca de óleo, de filtros e lubrificação de veículos, lavagem de veículos e atividade de loja de conveniência. Essas atividades, em função dos produtos manipulados (combustíveis e derivados), são consideradas potencialmente poluidoras, podendo, em caso de acidentes, causar impactos ambientais (LORENZETT e ROSSATO, 2010).

\section{METODOLOGIA DA PEQUISA}

Segundo Marconi e Lakatos (2005), esta etapa do trabalho consiste do estudo dos procedimentos adotado pelo pesquisador, consistindo na ordem ou sequência a ser seguida no desenvolvimento da pesquisa de forma a facilitar o trabalho de quem pesquisa, fornecendo a ele maior clareza em função da maneira como são apresentadas as proposições por ele elencadas.

Quanto à abordagem da pesquisa o trabalho classificou-se como pesquisa qualitativa, uma vez que não existe certeza absoluta no que está sendo pesquisado. Essa abordagem preocupa-se com o nível de verdade que não pode ser quantificado. O método qualitativo é para Richardson (2008, p. 79), aquele que "não faz uso de procedimentos estatísticos para análise do problema". Trata-se do método que tenta entender sua natureza do problema, por meio da observação e da descrição, remetendo ao subjetivismo e atribuindo um caráter indutivo à pesquisa.

Em relação aos objetivos, esta pesquisa foi considerada descritiva. A pesquisa descritiva é definida por Andrade (1999, p.106), como aquela onde os fatos "são observados, registrados, analisados, classificados e interpretados, sem que o pesquisador interfira neles". Para Lorenzett e Rossato (2010, p. 118), trata-se "da observação das situações e relações que ocorrem com o objeto estudado, sem que para isso, haja interação do pesquisador com o objeto alvo de estudo".

Este trabalho também foi considerado exploratório, pois o problema aqui estudado é recente e pouco explorado. A pesquisa exploratória segundo Andrade (1999, p.106), deve "proporcionar maiores informações sobre determinado assunto (...) definir os objetivos ou formular as hipóteses de uma pesquisa ou descobrir novo tipo de enfoque para o trabalho que se tem em mente". Logo, este trabalho firma-se como um trabalho inicial que servirá de base para futuros trabalhos na área, uma vez que ele pretendeu descobrir as relações existentes entre os componentes do objeto de estudo proporcionando maior detalhamento acerca do assunto.

No que tange os procedimentos técnicos, esta pesquisa fez uso, basicamente de quatro procedimentos, iniciando com o procedimento da pesquisa documental, partindo em seguida, para a pesquisa de campo, e conjuntamente a estes, fez uso da técnica da observação e da técnica da entrevista estruturada para coleta de dados.

A pesquisa documental é, para Marconi e Lakatos (2005), a pesquisa que possui como característica fundamental a fonte de coleta de dados restrita a documentos, escritos ou não, constituindo o que se denomina de fontes primárias, como fotos, leis, jornais e gravações, ou seja, são fontes que ainda não receberam tratamento, ou que ainda não foram "publicadas".

Na pesquisa de campo foi realizada a observação das instalações do posto de combustível e identificados os gastos associados às medidas de gestão ambiental adotadas. Segundo Severino (2007, p. 123), na pesquisa de campo a coleta de dados "é feita nas condições naturais em que os fenômenos ocorrem, sendo assim diretamente observados, sem intervenção e manuseio por parte do pesquisador". Ou seja, consiste na observação dos fenômenos e da coleta de dados para posterior análise. 
Quanto à técnica de coleta de dados, foi considerado o procedimento da observação, que para Martins (2006, p.23), consiste "em um exame minucioso que requer atenção na coleta e análise dos dados". Devendo, portanto, ser muito bem planejada. Para complementação da coleta de dados, foi considerada a técnica da entrevista estruturada, que para Cervo e Bervian (2006), consiste numa conversa predefinida cujo objetivo é a obtenção de dados para a pesquisa. De acordo com Marconi e Lakatos (2005, p.199), na entrevista estruturada “o pesquisador não é livre para adaptar suas perguntas a determinada situação, de alterar a ordem dos tópicos ou de fazer outras perguntas."

\section{RESULTADO E DISCUSSÕES}

\subsection{Gastos associados às medidas de gestão ambiental}

A seguir são apresentados, no Quadro 1, os gastos incorridos pelo posto de combustível para a implementação das medidas de gestão ambiental, bem como sua classificação quanto aos grupos patrimoniais. Para a classificação contábil desses gastos foram considerados os seguintes grupos patrimoniais: ativos ambientais, custos ambientais e despesas ambientais.

Os gastos relacionados aos investimentos sejam eles temporários ou não, são classificados, segundo a definição de ativo realizada por Santos, Schmit e Machado (2005), como ativos operacionais, pois são bens decorrentes de transações passadas, ou seja, a aquisição no momento da implantação do posto, no período da licença de implantação (LI), que estão à disposição da entidade, e proporcionarão, a ela, efetivos benefícios econômicos futuros de forma segura, sem prejudicar o meio ambiente.

Quadro 1 - Classificação dos gastos relacionados às medidas de gestão ambiental

\begin{tabular}{|c|c|}
\hline Classificação & Gastos relacionados às de Gestão Ambiental \\
\hline Ativos Operacionais & $\begin{array}{l}\text { - } \quad \text { Compra de tanques ecológicos; } \\
\text { - } \quad \text { Implantação das canaletas metálicas nas áreas de risco; } \\
\text { - Aquisição das bombas eletrônicas de abastecimento. }\end{array}$ \\
\hline Ativos Ambientais & $\begin{array}{l}\text { - } \quad \text { Construção da unidade coletora de água da chuva; } \\
\text { - } \quad \text { Construção do reservatório para estocagem da água da chuva; } \\
\text { - } \quad \text { Construção da caixa separadora de água e óleo; } \\
\text { - Implantação do poços de monitoramento; } \\
\end{array}$ \\
\hline Custos Ambientais & $\begin{array}{l}\text { - } \quad \text { A utilização das flanelas no abastecimento; } \\
\text { - Gastos com a realização de treinamento de pessoal para resposta a } \\
\text { incidentes ambientais; } \\
\text { - Os dispêndios com análises laboratoriais para verificação da qualidade } \\
\text { das águas subterrâneas; } \\
\text { - Gastos com manutenção das válvulas e suspiros dos tanques } \\
\text { - } \quad \text { Gabterrâneos; } \\
\text { - Gastos com manutenção da caixa separadora; } \\
\text { - } \quad \text { Gastos com o recolhimento de resíduos; } \\
\text { - Gastos com o recolhimento de óleo queimado; } \\
\end{array}$ \\
\hline Despesas Ambientais & $\begin{array}{l}\text { - Pagamento de taxas a órgão ambiental; } \\
\text { - } \quad \text { Pagamento das taxas de alvarás ambientais; } \\
\text { - } \quad \text { Pagamento de licenças ambientais. }\end{array}$ \\
\hline
\end{tabular}

Fonte: Pesquisa (2010)

Já os dispêndios que se restringem única e exclusivamente ao Meio Ambiente, e não a 
atividade fim da empresa, conforme definições de Ribeiro, Gonçalves e Lima (2002), devem ser registradas como ativos ambientais, pois estão ligados exclusivamente a proteção, preservação e recuperação ambiental. Assim, os recursos controlados pela entidade, cujos benefícios futuros esperados estão diretamente e exclusivamente associados com a proteção do meio ambiente, ou com a recuperação daquele já degradado, com vida útil superior a um ano, com intuito de reduzir ou eliminar a emissão de agentes poluentes, incluso as áreas nativas mantidas para conservação, são considerados de acordo com o IBRACON (1996), em literatura específica, como ativos ambientais.

Os gastos relacionados à manutenção das atividades, são classificados como custos ambientais, uma vez que segundo a definição de custo dada pelo CFC (2009), os custos de natureza ambiental serão aqueles consumidos no processo produtivo com o objetivo de reduzir e prevenir danos ambientais causados pelas atividades operacionais ou outros consumos vinculados à produção, desde que reconhecidos pela entidade.

Estes custos ambientais, segundo Ribeiro (2006), são aqueles relacionados, diretamente ou indiretamente com a proteção do meio ambiente, sendo, portanto, os valores despendidos nas atividades desenvolvidas com o propósito de controle, preservação e recuperação ambiental. A autora afirma que esses gastos empregados na área ambiental, que se comportam como custos, podem ser agregados ao custo de produção, para isso é necessário que eles melhorem a eficiência nas atividades da empresa e sejam passíveis de identificação.

Os gastos relacionados ao pagamento de taxas são classificados como despesas ambientais, uma vez que segundo as definições de Iudícibus et al. (2006), estas consistem no consumo de bens e serviços, que ajudam a produzir uma receita, direta ou indiretamente, e para o CFC (2009), são gastos gerais relacionados ao meio ambiente, desde que realizados no período.

Ribeiro (2006) também corrobora essa classificação, ao considerar como despesas ambientais, todos os gastos envolvidos no gerenciamento ambiental, que sejam consumidos no período e incorporados na área administrativa, nesse sentido, serão consideradas despesas ambientais, todas aquelas incorridas em qualquer departamento que desenvolva atividades relacionadas à proteção ambiental. Nessa etapa do estudo foram realizadas a identificação e classificação dos gastos relacionados às atividades de gestão ambiental. A próxima etapa do trabalho explicita como deve ser realizado o reconhecimento e a evidenciação contábil desses gastos.

\subsection{Reconhecimento contábil dos gastos vinculados às medidas de gestão ambiental no segmento de abastecimento de combustíveis}

A seguir é apresentado o Quadro 2, que demonstra quanto à classificação anteriormente realizada (ativos, custos e despesas ambientais), quais os gastos e em que momento deve ser realizado seu reconhecimento contábil.

Os gastos com a realização de investimentos circulantes e não circulantes exclusivos para a proteção, preservação e recuperação do Meio Ambiente devem ser reconhecidos como ativos ambientais, sendo contabilizados pelo seu valor de aquisição, ou seja, seu valor original, expressos em moeda corrente do país a valor presente, imediatamente após a aquisição, atendendo a tempestividade, ou seja, a informação é gerada em tempo certo refletindo a realidade do fato contábil, conforme princípio do registro pelo valor original e princípio da oportunidade 
respectivamente.

Os gastos realizados para a manutenção das atividades, inclusive aqueles referentes à depreciação de equipamentos e instalações e suas respectivas manutenções, devem ser reconhecidos como custo, no momento de sua ocorrência, ou seja, quando de sua utilização nas atividades desenvolvidas, em consonância com o princípio da competência.

Em relação a estes custos a NBC TE do CFC (2009) menciona que eles devem ser reconhecidos no período em que houver o consumo do recurso e confrontados com a receita a que estiverem associados, e serão classificados como de prestação de serviços se estiverem associados a ela, direta ou indiretamente, ou serão incorporados ao custo das mercadorias vendidas, quando configurarem gastos decorrentes das externalidades causadas pela entidade.

Quadro 2 - Momento do reconhecimento contábil

\begin{tabular}{|c|c|c|}
\hline \multirow{2}{*}{$\begin{array}{c}\text { Classificação } \\
\text { Ativos }\end{array}$} & \multicolumn{2}{|c|}{ Reconhecimento contábil dos gastos ambientais } \\
\hline \multirow{2}{*}{$\begin{array}{c}\text { ambientais } \\
\text { Custos }\end{array}$} & Quando gastos & $\begin{array}{c}\text { Aqueles para realização de investimentos circulantes e não } \\
\text { circulantes exclusivamente relacionados com o Meio Ambiente. }\end{array}$ \\
\cline { 2 - 3 } ambientais & Quais gastos & $\begin{array}{c}\text { Aqueles realizados para a manutenção das atividades de proteção } \\
\text { preservação e recuperação ambiental. }\end{array}$ \\
\cline { 2 - 3 } & Quando & $\begin{array}{c}\text { No momento da utilização dos insumos e da mão-de-obra nas } \\
\text { atividades desenvolvidas e com extensão exata. }\end{array}$ \\
\hline \multirow{2}{*}{ Despesas } & Quais gastos & $\begin{array}{c}\text { Gastos referentes a pagamentos de taxas e licenças ambientais, ou } \\
\text { seja, despesas de ordem geral relacionados ao Meio Ambiente. }\end{array}$ \\
\cline { 2 - 3 } ambientais & Quando & $\begin{array}{c}\text { No momento da utilização dos insumos e da mão-de-obra nas } \\
\text { atividades de gerenciamento ambiental, no setor administrativo. }\end{array}$ \\
\hline
\end{tabular}

Fonte: Pesquisa (2010)

Ribeiro (2006) discorre sobre o assunto, enfatizando que o reconhecimento dos custos ambientais se processa na mesma proporção em que beneficiar o exercício em curso, sendo levada ao resultado do exercício em que seu fato gerador ocorreu. A autora entende que os custos prévios utilizados para redução da poluição em períodos posteriores devem ser estimados e alocados ao exercício em curso, onde o fato gerador ocorreu, sendo reconhecidos à medida que forem ocorrendo, ou seja, em mais de um período, quando for o caso. Entende, ainda, que o custo decorrente da gestão ambiental, que existe concomitantemente à atividade econômica explorada deve ser regularmente contabilizado, segregadamente em contrapartida as receitas obtidas no período.

Os gastos referentes a pagamentos de taxas e licenças ambientais devem ser reconhecidos no momento da utilização dos insumos e da mão-de-obra nas atividades de gerenciamento ambiental, no setor administrativo como despesas, devendo ser levados a apuração do resultado em que ocorrerem, independentemente de seu pagamento, conforme determina o princípio da competência, este registro deve ser imediato, ou seja, no momento de sua ocorrência, segundo principio da oportunidade.

O CFC (2009) entende que as despesas devem ser reconhecidas na medida em que ocorrem, para suprir a relação da entidade com o meio ambiente, não podendo ser associada 
aos produtos ou processos específicos da atividade desenvolvida. Portanto, elas devem ser classificadas no corpo da demonstração de resultado (DRE), entre as despesas de venda, administrativas e gerais, segregadas em grupo à parte. No tocante à avaliação, elas devem ser avaliadas pelo valor do consumo no momento em que ele ocorreu. Ribeiro (2006) salienta que as despesas devem ser contabilizadas como despesas do exercício em que ocorreram, ainda que possam ter alguma relação com benefícios futuros, nos casos em que dificilmente poderiam ser associados ou mensurados com clareza.

É importante que todo esse processo de classificação e reconhecimento contábil desses gastos associados às medidas de gestão ambiental se reflita nas demonstrações contábeis, de forma a se efetivar a evidenciação de tais gastos, imprimindo maior transparência e confiabilidade a essas demonstrações, mas principalmente tornando-as mais adequadas para efeito de análises gerenciais.

\subsection{Evidenciação contábil dos gastos vinculados às medidas de gestão ambiental no segmento de abastecimento de combustíveis}

A NPA 11 do IBRACON (1996) estabelece que a contabilidade deve refletir as interações das empresas com o meio ambiente; que essa interação deve ser demonstrada no corpo das demonstrações contábeis, em títulos específicos, identificando adequadamente os elementos patrimoniais, ativos e passivos ambientais, complementada, ainda, por notas explicativas, onde conste a real posição ambiental da entidade, devendo a empresa quando reconhecida como potencialmente poluidora, fazer provisões para possíveis contingências futuras. Complementando, a NBC T 15 do CFC (2004), estabelece que, na contabilidade das entidades, devem ser evidenciados os investimentos e gastos despendidos na interação da empresa com o meio ambiente.

De forma a garantir a divulgação dessas informações ambientais foi criada a NBC TE do CFC (2009), onde está estabelecido que o plano de contas deve contemplar as contas referentes à interação da entidade com o meio ambiente, de forma segregada das demais contas, sendo as demais informações relevantes, citadas em notas explicativas. Deve-se, portanto, construir um plano de contas, que contemple de forma segregada, as contas específicas relativas à interação da entidade com o meio ambiente, ou seja, este novo plano de contas deve apresentar as contas de ativos ambientais, despesas ambientais e custos ambientais, possibilitando maior transparência, em relação à questão ambiental nas demonstrações, e uma série de novas análises gerenciais aos gestores, pois eles poderão identificar claramente o quanto estão gastando em gestão ambiental e o quão representativo isso pode ser para a entidade.

\section{CONSIDERAÇÕES FINAIS}

Atualmente, o Brasil, vive uma fase onde o equilíbrio ambiental está em ascensão, os órgãos ambientais estão cada vez mais atuantes, e a legislação cada vez mais rigorosa. Com vistas a isso, o Conselho Federal de Contabilidade (CFC) lançou em 2009 a NBC TE, evidenciando a importância da contabilidade refletir as relações da entidade com o meio no qual está inserida, e abrindo um novo ramo de atividade para os contadores, a Contabilidade Ambiental. A referida norma objetiva a definição dos conceitos, bem como estabelece critérios para a contabilização 
de eventos e transações ambientais. Ela vem para esclarecer os critérios que devem ser adotados para o reconhecimento, classificação, mensuração e evidenciação no que concerne a interação da entidade com o meio ambiente.

Este trabalho teve por foco principal demonstrar o adequado reconhecimento contábil dos gastos associados às medidas de gestão ambiental no segmento de abastecimento de combustíveis. Para tanto foi realizada uma pesquisa de campo junto a um estabelecimento desse ramo de atividade, para entender como se processam as atividades de forma a se identificar os gastos decorrentes da adoção de medidas de gestão ambiental que proporcionam uma interação mais harmoniosa da empresa com o meio ambiente, uma vez que os órgãos ambientais a classificam como atividade potencialmente poluidora.

No decorrer do estudo, por meio da entrevista estruturada, identificaram-se os gastos com gestão ambiental inerentes à atividade, os quais foram classificados como ativos ambientais, despesas ambientais e custos ambientais, de acordo com literatura específica, à luz das normas brasileiras de contabilidade. Pode-se mencionar como principais gastos classificados como Ativos Ambientais aqueles relacionados única e exclusivamente com a proteção e preservação do meio ambiente, como é o caso da construção de estruturas seguras que reduzem a possibilidade de vazamentos e de contaminação do meio ambiente, além da construção de mecanismos para o tratamento dos efluentes líquidos, que possibilitam o desenvolvimento das atividades de forma limpa e segura.

Já os principais Custos Ambientais compõem o rol de gastos despendidos com a manutenção das atividades de controle e preservação ambiental, como: o recolhimento dos resíduos por empresas especializadas, a manutenção das válvulas dos tanques reservatórios de combustível e a manutenção da caixa separadora de água e óleo. Para Ribeiro (2006), constituem-se em custos ambientais todos aqueles gastos que estão relacionados, diretamente ou indiretamente com a proteção do meio ambiente.

Com relação às despesas ambientais, foi constatado que consistem basicamente de taxas e licenças pagas aos órgãos ambientais, pois, segundo Ribeiro (2006), são consumos referentes às atividades administrativas da entidade, que não geram expectativa benefícios futuros. Analisou-se, também, o reconhecimento contábil desses gastos, de acordo com os padrões de contabilização brasileiros, onde foi detectado que o momento ideal para o seu reconhecimento seria: para os Ativos Ambientais, quando de sua aquisição; para os custos ambientais, quando do seu consumo nas atividades; e para as despesas ambientais, estas devem ser reconhecidas no momento da utilização dos insumos e da mão-de-obra nas atividades de gerenciamento ambiental, no setor administrativo, devendo ser levadas ao resultado do exercício a que beneficiaram.

Em relação à evidenciação contábil desses gastos, entendeu-se que a forma mais adequada para sua evidenciação seria em contas específicas ambientais inseridas no corpo das demonstrações contábeis já existentes, permitindo a realização de uma série de análises gerenciais, a partir da comparação dos valores de tais contas com as demais contas das demonstrações contábeis, imprimindo, dessa forma, um caráter gerencial a contabilidade empresarial.

Para futuras investigações, fica a sugestão de trabalhar comparativamente, estudando um posto de combustível que esteja adequado às normas e um que não esteja adequado, comparandose os gastos, para verificar a viabilidade econômico-financeira da adoção de medidas de gestão ambiental, bem como para testar a restritividade da legislação ambiental vigente. 


\section{REFERÊNCIAS}

ANDRADE, Maria Margarida de. Introdução a metodologia do trabalho científico: elaboração de trabalhos na graduação. 4. ed. São Paulo: Atlas, 1999.

BARROS, Paulo Eduardo Oliveira de. Diagnostico ambiental para postos de abastecimento de combustíveis: DAPAC. Itajaí: Universidade do Vale do Itajaí, 2006.

BENNET, M., et al. Environmental management accounting: informational and institutional developments. Kluwer Academic Publishers, Dordrecht, 2004.

BERTOLI, Ana Lúcia; RIBEIRO, Maisa de Souza. Passivo ambiental: estudo de caso da Petróleo Brasileiro S.A - Petrobrás. A repercussão ambiental nas demonstrações contábeis, em conseqüência dos acidentes ocorridos. Rev. adm. contemp., Curitiba, v. 10, n. 2, jun. 2006 . Disponível em: $<$ http://www.scielo.br/scielo.php?script=sci_arttext\&pid=S141565552006000200007\&lng=pt\&nrm=iso $>$. Acesso em; 24 de Mai. 2011. doi: 10.1590/S141565552006000200007 .

CERVO, Amado Luiz; BERVIAN, Pedro Alcino. Metodologia científica. 5. ed. São Paulo: Pearson Prentice Hall, 2006.

CFC. NBC TE: Interação da entidade com o meio ambiente. Brasília: CFC, 2009. Disponível em: $\quad<\mathrm{http} / / /$ www.cfc.org.br/uparq/NBC_TE_INTERACAO_DA_ENTIDADE_MEIO AMBIENTE.pdf $>$. Acesso em: 10 de Out. $200 \overline{9}$.

NBC T: NBC T 15 - Informações de natureza social e ambiental. Brasília: CFC, 2004. Disponível em: <http://www.portaldecontabilidade.com.br/nbc/t15.htm>. Acesso em: $12 \mathrm{de}$ Nov. 2009. $\overline{2008}$.

Princípios fundamentais e normas brasileiras de contabilidade. 3.ed. Brasília: CFC,

COLEMAN, Les. Losses from failure of stakeholder sensitive processes: financial consequences for large US companies from breakdowns in product, environmental, and accounting standards. Journal of Business Ethics, v. 98, n. 2, p. 247-258, 2011. Disponível em: <http://www. springerlink.com/content/e1178978hk37r125/>. Acesso em: 26 de Mai. 2011. doi: 10.1007/ s10551-010-0544-8

COSTA, Rodrigo Simão da; MARION, José Carlos. A uniformidade na evidenciação das informações ambientais. Revista contabilidade e finanças, São Paulo, v. 18, n. 43, abr. 2007. Disponível em: $<$ http://www.scielo.br/scielo.php?script=sci_arttext\&pid=S151970772007000100003\&lng=pt\&nrm=iso $>$. Acesso em: 20 de Mai. 2011. doi: 10.1590/S151970772007000100003 .

FARONI, Walmer et al . A contabilidade ambiental em empresas certificadas pelas normas ISO 14001 na região metropolitana de Belo Horizonte-MG. Revista Árvore, Viçosa, v. 34, n. 6, dez. 2010. Disponível em: $<$ http://www.scielo.br/scielo.php?script=sci_arttext\&pid=S010067622010000600018\&lng=pt\&nrm=iso $>$. Acesso em: 25 de Mai. 2011. doi: 10.1590/S010067622010000600018 .

FRANCO, Hilário. Contabilidade geral. 23. ed. São Paulo: Atlas, 1997.

IBRACON. Publicações: NPAS, NPA11: balanço e ecologia. São Paulo: IBRACON, 1996. Disponível em: 
$<$ http://www.ibracon.com.br/publicacoes/resultado.asp?identificador=223>. Acesso em: 25 de Out. 2009.

IUDICI BUS, Sergio de. (coord.). et al. Contabilidade Introdutória. 10. ed. São Paulo: Atlas, 2006.

JORDAN, Stephen J. et al. Accounting for natural resources and environmental sustainability: linking ecosystem services to human well-being. Environmental Science \& Technology. v. 44, n. 5, p. 1530-1536, 2010. Disponível em: <http://pubs.acs.org/doi/pdf/10.1021/es902597u>. Acesso em: 27 de Mai. 2011. doi: 10.1021/es902597u.

LIMA, Diana Vaz de; VIEGAS, Waldyr. Tratamento contábil e evidenciação das externalidades ecológicas. Revista Contabilidade e Finanças - USP, São Paulo, n. 30, p. 46-53, set. 2002. Disponível em: $<$ http://www.eac.fea.usp.br/cadernos/completos/cad30/revista_30_parte4.pdf $>$. Acesso em: 23 de Mai. 2011.

LORENZETT, Daniel Benitti; ROSSATO, Marivane Vestena. A gestão de resíduos em postos de abastecimento de combustíveis. Revista Gestão Industrial, Ponta Grossa, PR, v. 6, n. 2, p. 110-125, 2010. Disponível em: <http://www.pg.utfpr.edu.br/depog/periodicos/ index.php/revistagi/article/view/598/479>. Acesso em: 30 de Jun. 2010. doi: 10.3895/S180804482010000200006.

MARTINS, Eliseu; RIBEIRO, Maisa de Souza. A Informação como Instrumento de Contribuição da Contabilidade para a Compatibilização do Desenvolvimento Econômico e a Preservação do Meio Ambiente. Revista Interamericana de Contabilidade, n. 60, p. 31-40, out 1995.

MARTINS, Gilberto de Andrade. Estudo de caso: uma estratégia de pesquisa. São Paulo: Atlas, 2006.

MARCONI, Maria de Andrade; LAKATOS, Eva Maria. Fundamentos de metodologia científica. 6. ed. São Paulo: Atlas, 2005.

ORGANIZAÇÃO DAS NAÇÕES UNIDAS. The Intergovernamental Working Group of Experts on Internetional Standards of Accounting and Reporting. Objectives and concepts underlying financial statements. New York, 1989. p. 14-22.

PROTOGEROS, N. et al. A software shell for environmental accounting. Environmental modelling \& software. v. 26, n. 2, p. 235-237, 2011. Disponível em: <http://www. sciencedirect.com/science? ob=MImg\&_imagekey=B6VHC-50S2DH1-1-3\&_cdi=6063\&_ user $=687358 \& \_$pii $=$S $1364 \overline{8} 152100020 \overline{70} \&$ origin $=\&$ coverDate $=02 \% 2 \mathrm{~F} 2 \overline{8} \% 2 \mathrm{~F} 2011 \&^{-}$ $\mathrm{sk}=999739997 \& \mathrm{view}=\mathrm{c} \& \mathrm{wchp}=\mathrm{dGLzVzb}-\mathrm{zSkzk} \& \mathrm{md} 5=7 \mathrm{baafd} 4052 \mathrm{e} 597 \mathrm{a} 8 \mathrm{c} 59 \mathrm{~d} 4440 \mathrm{f} 2 \mathrm{aa} 3 \overline{5}$ 66\&ie=/sdarticle.pdf $>$. Acesso em: 26 de Mai. 2011. doi:10.1016/j.envsoft.2010.07.003.

RAUPP, Elena Hahn. Desenvolvimento sustentável: a contabilidade num contexto de responsabilidade social de cidadania e de meio ambiente. Revista de Contabilidade do CRC SP. São Paulo, n. 20, p. 46-60, 2002.

RIBEIRO, Maisa de Souza. Contabilidade ambiental. 2. Tiragem. São Paulo: Saraiva, 2006.

; GONÇALVES, R. C. M. G.; LIMA, S. A. Aspectos de contabilização do passivo e ativo ambientais nas termelétricas brasileiras. Revista de Contabilidade do CRC SP. São Paulo, n. 20, p. 4-12, 2002.

;LISBOA, Lázaro Plácido. Balanço Social. Revista Brasileira de Contabilidade, Brasília, DF, n. 115, p. 72-81, 1999. 
RIBEIRO, Osni Moura. Contabilidade básica: fácil. 23. ed. São Paulo: Saraiva, 1999.

RICHARDSON, Roberto Jarry. Pesquisa social: métodos e técnicas. 3. ed. 9. Reimpressão. São Paulo: Atlas, 2008.

SANTOS, Jose Luiz dos; SCHMIDT, Paulo; MACHADO, Nilson Perinazzo. Fundamentos da teoria da contabilidade. v. 6. Coleção resumos de contabilidade. São Paulo: Atlas, 2005.

SANTOS, Ricardo José Shamá dos. A gestão ambiental em posto revendedor de combustíveis como instrumento de prevenção de passivos ambientais. 2005. 217f. Dissertação (Mestrado em Sistemas de Gestão do Meio Ambiente) - Universidade Federal Fluminense, Niterói, 2005.

SOUZA, Valdiva Rossato de; RIBEIRO, Maisa de Souza. Aplicação da contabilidade ambiental na indústria madeireira. Revista Contabilidade e Finanças - USP. São Paulo, n. 35, p. 5467, mai. 2004. Disponível em: <http://www.eac.fea.usp.br/cadernos/completos/cad35/ed_35_ parte5_pg54a67.pdf $>$. Acesso em: 22 de Mai. 2011.

SEVERINO, Antônio Joaquim. Metodologia do trabalho científico. 23. ed. São Paulo: Cortez Editora, 2007.

TINOCO, João Eduardo Prudêncio; KRAEMER, Maria Elisabeth Pereira. Contabilidade e gestão ambiental. São Paulo: Atlas, 2004.

WEISS, Nélio Badauy. A elevadíssima carga tributária - quosque tandem?. 2010. Palestra Realizada no simpósio "Justiça federal e sociedade: simpósio nacional de direito tributário em homenagem à ministra Eliana Calmon. Abordagens jurídicas e contábeis” em 18 mai. 2010. 


\section{ENDEREÇO DOS AUTORES:}

\section{Daniel Benitti Lorenzett}

Universidade Federal de Santa Maria, Centro de Tecnologia - Programa de Pós-Graduação em Engenharia de Produção.

Avenida Roraima - Cidade Universitária, P. 07, 3 andar, Sala 319 Camobi

Santa Maria, RS - Brasil

97105-900

\section{Marivane Vestena Rossato}

Universidade Federal de Santa Maria, Centro de Ciências Sociais e Humanas, Departamento de Ciências Contábeis.

Rua Floriano Peixoto, n. 1184, sala 602 Centro

Santa Maria, RS - Brasil

97015-372

\section{Leoni Pentiado Godoy}

Universidade Federal de Santa Maria, Centro de Tecnologia - Programa de Pós-Graduação em Engenharia de Produção.

Avenida Roraima - Cidade Universitária, P. 07, 3 andar, Sala 319 Camobi

Santa Maria, RS - Brasil

97105-900 